\title{
Perancangan Sistem Informasi Perhitungan Caddie Fee Pada Imperial Klub Golf Karawaci Kabupaten Tangerang
}

\author{
Sukisno \\ Jurusan Teknik Informatika TI Universitas Islam Syekh-Yusuf \\ Jln. Maulana Yusuf No 10 - Babakan Kota Tangerang \\ sukisno@unis.ac.id
}

\begin{abstract}
Intisari-Sistem perhitungan caddie fee di imperial klub golf saat ini masih dilakukan secara manual. Data-data perhitungan caddie fee disimpan dalam bentuk berkas, sehingga kurang efektif dan efisien. Tujuan penelitian ini adalah membuat sistem informasi perhitungan caddie fee dengan manfaat yaitu memudahkan dalam proses menghitung caddie fee dan supaya sistem informasi ini memberi dukungan pada kelancaran tugas bagian caddie master dalam menghitung caddie fee. Sesuai dengan tujuan penelitian, maka penelitian ini dilakukan dengan metode analisis, perancangan system dan pembuatan program. Objek penelitian ini adalah imperial klub golf karawaci kabupaten tangerang. Dari hasil penelitian dapat disimpulkan bahwa system informasi yang dikembangkan yaitu system informasi perhitungan caddie pada imperial klub golf karawaci kabupaten tangerang lebih efisien, cepat dan akurat daripada system yang ada yang masih dilakukan secara manual.

Kata kunci-Perhitungan Caddie Fee, Imperial Klub Golf
\end{abstract}

Abstract - Caddy fee calculation system at the imperial klub golf is currently still done manually. Caddy fee calculation data is stored in file form, making it less effective and efficient. The purpose of this study is to create a caddy fee calculation information system with the benefit of facilitating the process of calculating caddy fees and so that this information system provides support for the smooth task of the caddy master section in calculating caddy fees. In accordance with the objectives of the study, this research was conducted with the method of analysis, system design and program making. The object of this research is the imperial klub golf Karawaci, Tangerang district. From the results of the study it can be concluded that the information system developed is the caddy calculation information system at the imperial klub golf Karawaci Tangerang district is more efficient, fast and accurate than the existing system that is still done manually.

Keywords - Calculation of Caddy Fee, Imperial Klub Golf

\section{Pendahuluan}

Teknologi komputer yang semakin berkembang pesat saat ini telah banyak memberikan manfaat dan kemudahankemudahan sehingga banyak digunakan di berbagai bidang. Seiring dengan perkembangan teknologi ini telah makin banyak bidang yang mulai beralih ke sistem komputer terutama untuk persoalan pengolahan penyimpanan data, serta pengaturan sistem yang biasanya dilakukan secara manual dan membutuhkan tenaga dan pikiran yang besar.

Komputer adalah alat yang dipakai untuk mengolah data menurut prosedur yang telah dirumuskan yang secara otomatis menerima, menyimpan data untuk menghasilkan informasi yang merupakan hasil dari pemrosesan itu.
Suatu perusahaan dalam menjalankan kegiatannya harus didukung oleh sumber daya fisik yaitu mesin, manusia dan materi.

Kemudahan dalam melakukan proses pengolahan data serta kemajuan teknologi komputer, maka banyak perusahaan atau instansi pemerintah yang bergerak dalam bidang jasa, perdagangan dan industri mulai memakai sistem komputerisasi. Ini sangat penting dalam perkembangan perusahaan karena sistem tersebut sangat membantu dalam hal perhitungan dan proses pengolahan data.

Sistem perhitungan caddie fee di imperial klub golf yang terletak di Jalan pulau golf lippo karawaci kabupaten tangerang ini masih dilakukan secara manual sehingga dalam keamanan data masih kurang terjamin serta proses penyediaan informasi cukup 
lama.Sehubungan dengan hal tersebut diatas,maka penulis bermaksud ingin membuat suatu program sederhana yang akan dituangkan dalam bentuk penulisan agar dapat membantu untuk memudahkan user dan pihak management,agar user mengetahui alur proses data yang lebih terkontrol secara cepat,tepat dan akurat serta mudah dalam penggunaan.

\section{A. Perumusan Masalah}

Bagaimana cara membuat rancangan suatu sistem informasi untuk mengolah data caddie fee pada imperial klub golf yang dapat memberikan informasi secara cepat,tepat dan akurat serta mudah dalam penggunaan.

\section{B. Ruang Lingkup}

Sistem yang akan dirancang adalah sebagai berikut:

a. Merancang sebuah sistem informasi tentang perhitungan caddie fee, mengelola data caddie dan data pemain.

b. Pembuatan laporan meliputi informasi data caddie,pemain dan laporan perhitungan caddie fee.

\section{Tujuan Penelitian}

Tujuan dari penelitian ini adalah sebagai berikut:

a. Untuk merancang dan membuat sistem informasi agar mengefesiensikan pemrosesan dan perhitungan caddie fee.

b. Untuk memberikan laporan data caddie,pemain dan laporan perhitungan caddie fee dengan cepat,tepat dan akurat.

\section{Manfaat penelitian}

Manfaat dari penelitian ini adalah sebagai berikut:

a. Digunakannya sistem aplikasi komputer pada imperial klub golf sehingga dapat menghasilkan informasi yang cepat,tepat dan akurat.

b. Lebih mempermudah pembuatan laporan,baik laporan keseluruhan,harian, mingguan maupun bulanan.Dimana laporan terbentuk lebih mudah untuk dipahami dan mengarah ke bentuk yang diharapkan.

\section{Metodologi Penelitian}

Bagian Metodologi penelitian adalah sekumpulan peraturan,kegiatan dan prosedur yang digunakan oleh pelaku suatu disiplin ilmu metodologi juga merupakan analitis teoritis mengenai suatu cara atau metode merupakan suatu penyelidikan yang sistematis untuk meningkatkan sejumlah pengetahuan, juga merupakan suatu usaha yang sistematis dan terorganisasi untuk menyelidiki masalah tertentu yang memerlukan jawaban. Hakekat penelitian dapat dipahami dengan mempelajari berbagai aspek yang mendorong penelitian untuk melakukan penelitian.Setiap orang mempunyai motivasi yang berbeda,diantaranya dipengaruhi oleh tujuan dan profesi masingmasing.Motivasi dan tujuan penelitian secara umum pada dasarnya adalah sama,yaitu bahwa penelitian merupakan refleksi dari keinginan manusia yang selalu berusaha untuk mengetahui sesuatu.Keinginan untuk memperoleh dan mengembangkan pengetahuan merupakan kebutuhan dasar manusia yang umumnya menjadi motivasi untuk melakukan penelitian.

\section{A. Metode Pengumpulan data}

Pengumpulan data dilakukan untuk memperoleh informasi yang dibutuhkan dalam rangka mencapai tujuan penelitian. Tujuan yang diungkapkan dalam bentuk hipotesis merupakan jawaban sementara terhadap pertanyaan penelitian. Jawaban itu masih perlu diuji secara empiris,dan untuk maksud inilah dibutuhkan pengumpulan data. Data yang dikumpulkan oleh sampel yang telah ditentukan sebelumnya. Sampel tersebut terdiri atas sekumpulan unit analisis sebagai sasaran penelitian.Dalam penulisan ini penulis menggunakan tiga metode penulisan yaitu:

a. Metode Wawancara

Dengan mengajukan pertanyaan secara langsung dengan pihak yang bersangkutan 
dengan berlandaskan pada tujuan penelitian dan objek yang diteliti.

b. Metode Kearsipan

Yaitu metode penelitian yang dilakukan dengan menggunakan arsip yang penulisan dari perusahaan dalam bentuk dokumen.

c. Metode Kepustakaan

Metode kepustakaan ini mengaju pada bukubuku pedoman yang dibutuhkan baik yang ada diperpustakaan,maupun literaturliteratur yang berhubungan dengan masalah yang diteliti sehingga nantinya dapat membantu selesainya penelitian ini.

\section{B. Metode Analisis Data}

Metode analisis data menggunakan teknik sebagai berikut:

a. UML(Unified Modelling Language)

Peneliti akan mempelajari terlebih dahulu UML pada sistem perhitungan caddie fee tersebut untuk mengidentifikasi kelemahan dari sistem yang akan dijadikan perbandingan terhadap masalah yang terjadi.

b. Kamus Data

Menggambarkan katalog fakta tentang data dan kebutuhan-kebutuhan informasi dari suatu sistem informasi.Dengan kamus data analisis sistem dapat mendefinisikan data yang mengalir di sistem dengan lengkap.

c. Rancangan Input dan Output

Menggambarkan hasil akhir dari rancangan yang dibuat.

\section{HASIL DAN PEMBAHASAN}

\section{A. Rancangan Fungsional(Functional Design)}

Rancangan sistem merupakan rancangan mekanisme kerja proses-proses yang dilakukan oleh sistem di dalam Sistem perhitungan caddie fee di Imperial Klub Golf Karawaci Kabupaten Tangerang ini.Rancangan Sistem perhitungan caddie fee di Imperial Klub Golf Karawaci Kabupaten Tangerang ini dibuat dengan menggunakan aplikasi Enterprise Architect yang berbasiskan UML(Unified Modeling Language)yang terdiri dari diagram use case, activity diagram, class diagram, sequence diagram. Sistem yang akan diusulkan,yaitu Sistem perhitungan caddie fee di Imperial Klub Golf Karawaci Kabupaten Tangerang yang dapat diakses dengan mudah cepat dan efisien.

Adapun gambaran dari sistem yang penulis rancang sebagai berikut:

1. Pemain dapat memilih pemandu golf (caddie) secara sistem.

2. Pemain dapat melihat data yang akurat dan cepat.

3. Caddie dapat langsung melihat pemain yang memilihnya.

4. Sistem perhitungan caddie fee yang transparan.

\section{B. Rancangan Prosedur}

Rancangan prosedur dari sistem perhitungan caddie fee di Imperial Klub Golf Karawaci Kabupaten Tangerang yang penulis rancang adalah sebagai berikut:

1. Admin menginput nomor id pemain dan id caddie di form transaksi.

2. Admin mengelola data pemain dan data caddie.

3. Caddie mengambil bag golf dan nama pemain ke admin.

4. Caddie menerima laporan data pemain dari admin dan menerima laporan caddie fee.

5. Caddie menerima hasil perhitungan total caddie fee dalam bentuk caddie fee list.

6. Caddie menerima list caddie fee per 2 minggu.

7. Pimpinan menerima list caddie fee.

\section{Usecase Diagram}

Scenario use case yang digunakan untuk memudahkan dalam menganalisis interaksi antara aktor dan use case dalam melakukan proses tertentu, scenario yang akan penulis gunakan pada tahapan- tahapan selanjutnya dengan melakukan penilaian terhadap scenario tersebut.

Nama Use case : :Mengelola data Actor 
Type

:Primary key

Tujuan :Pendataan caddie

Deskripsi

Admin masuk kehalaman utama dengan melakukan login terlebih dahulu, dan sistem menampilkan form login. Admin memasukan username dan password apabila sudah berhasil login sistem akan menampilkan halaman utama, admin bisa melakukan pengolahan data dan mencetak laporan dalam halaman utama. Kemudian admin bisa log out dan keluar dari sistem.

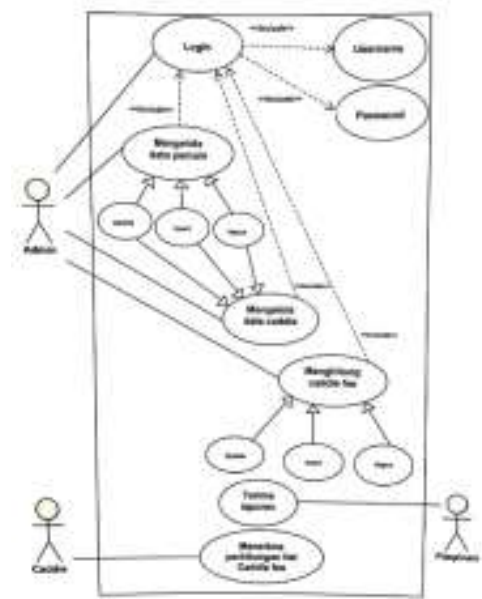

Gambar 1. Usecase Perhitungan Caddie Fee

\section{Activity Mengelola Data}

Activity diagram untuk mengelola data hanya dilakukan oleh administrator. Pada halaman administrator proses yang dapat dilakukan oleh admin adalah mengelola pemain, mengelola caddie dan membuat laporan yaitu dengan menambah, mengedit dan juga menghapus data.Hal ini karena administrator lebih berwenang untuk mengelola data.

a. Sistem menampilkan form login perhitungan caddie fee.

b. Administrator memasukkan username dan password.

c. Jika username dan password yang dimasukkan oleh administrator benar, maka sistem akan menampilkan menu utama dan jika salah, maka sistem akan kembali ke form login. d. Setelah masuk ke sistem, administrator melakukan managemen data pemain dan data caddie dengan menambah, update atau hapus data yang ada di database sehingga database dapat terupdate.

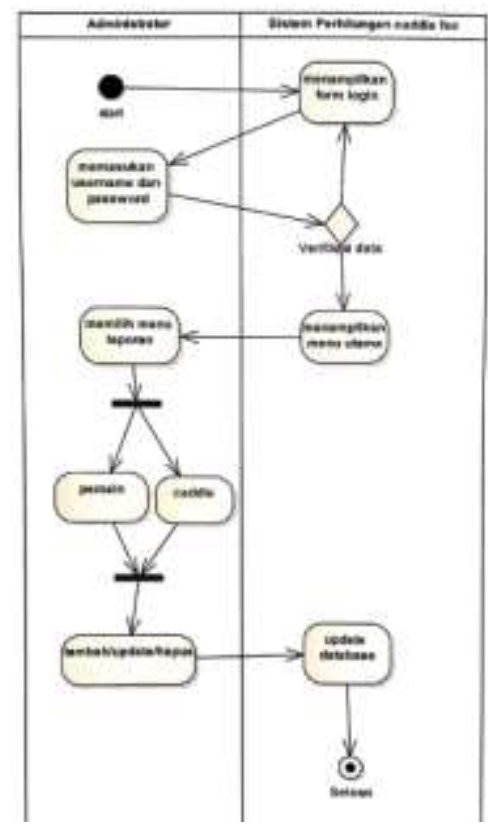

Gambar 2. Activity Mengelola Data

\section{E. Class Diagram}

Class diagram adalah sebuah spesifikasi yang jika diinstansiasi akan menghasilkan sebuah objek dan merupakan inti dari pengembangan dan desain berorientasi objek. Class menggambarkan keadaan(atribut/properti)suatu sistem. Sekaligus menawarkan layanan untuk manipulasi keadaan tersebut(metode/fungsi). Class diagram menggambarkan struktur dan deskripsi class,package dan object beserta hubungan satu sama lain seperti containmen, pewarisan dan lain-lain.

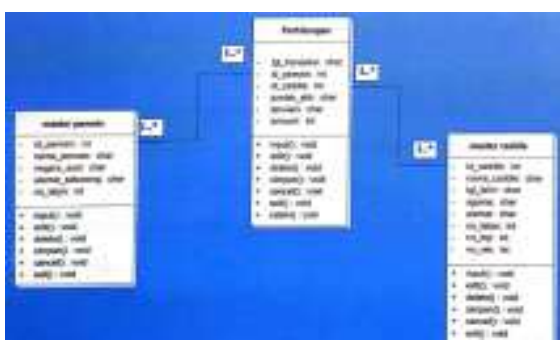

Gambar 3. Class Diagram 


\section{F. Sequence Diagram}

Sequence Diagram digunakan untuk menggambarkan interaksi antar objek dalam waktu yang berurutan. Tetapi pada dasarnya sequence diagram selain digunakan dalam lapisan abstraksi model objek. Kegunaannya untuk menunjukkan rangkaian pesan yang dikirim antara objek juga interaksi antara objek, sesuatu yang terjadi pada titik tertentu dalam eksekusi sistem.Komponen utama sequence diagram terdiri atas objek yang dituliskan dengan kotak segiempat bernama pesan diwakili oleh garis dengan tanda panah dan waktu yang ditunjukkan dengan proses vertikal. Berikut adalah sequence diagram yang diusulkan pada sistem perhitungan caddie fee.

Sequence ini menggambarkan beberapa proses yang terjadi pada use case mengelola caddie. Maintenance caddie hanya dapat dilakukan oleh admin. Admin dapat mengelola caddie antara lain menambah data, mengedit dan juga menghapus data caddie. Untuk lebih jelasnya dapat dilihat pada gambar sequence diagram berikut ini:

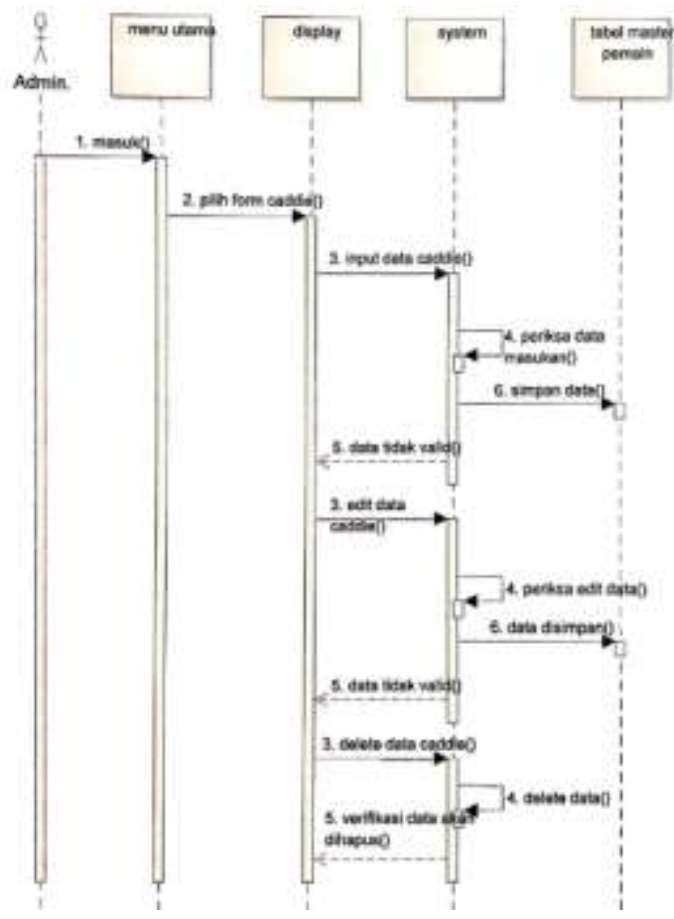

Gambar 4. Sequence Diagram Perhitungan Caddie Fee

\section{G. Tampilan Menu Utama}

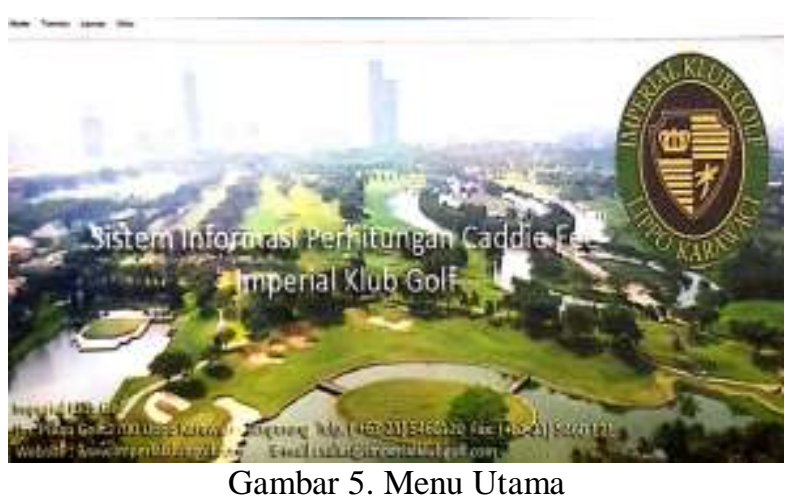

H. Tampilan Master Caddie

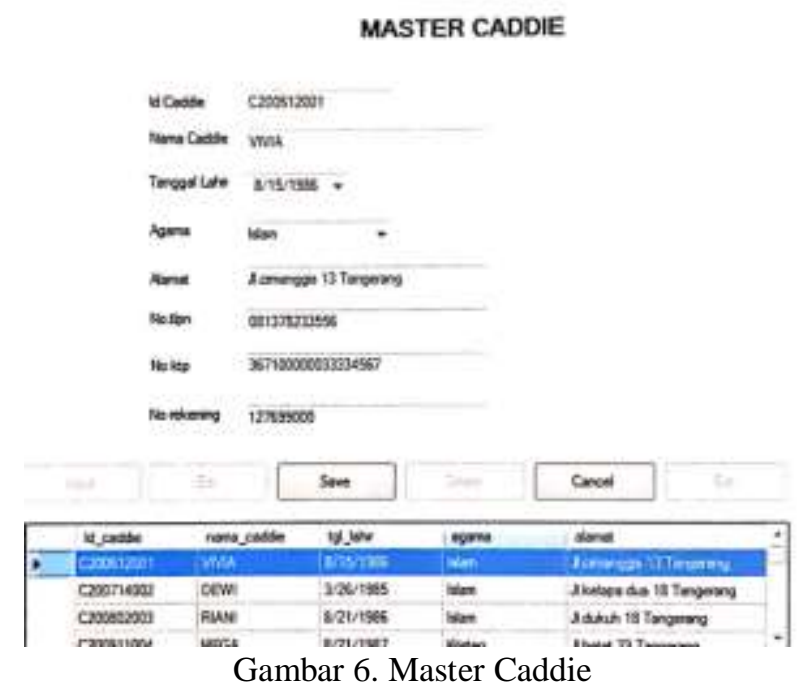

I. Tampilan Master Pemain

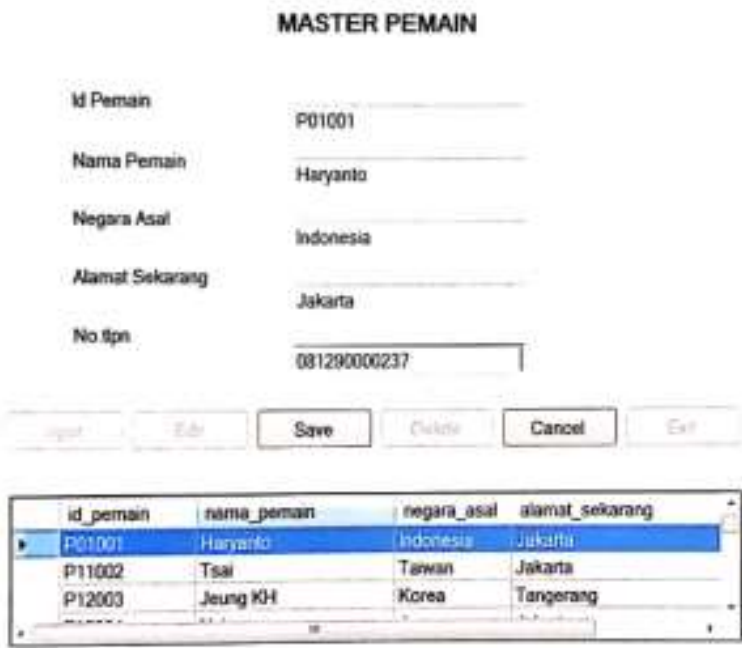

Gambar 7. Master Pemain 


\section{KESIMPULAN}

Kesimpulan Berdasarkan hasil penelitian yang dilakukan oleh penulis mengenai sistem informasi perhitungan caddie fee, maka dapat ditarik beberapa kesimpulan sebagai berikut:

1. Dengan sistem informasi perhitungan caddie fee yang terintegrasi dapat mempermudah pelayanan dan pengolahan data secara cepat dan efisien.

2. Sistem informasi perhitungan caddie fee ini dapat menghasilkan informasi yang akurat untuk laporan kepada pimpinan perusahaan sebagai perencanaan dan pengambilan keputusan.

3. Dengan adanya sistem ini, data-data yang sebelumnya dikerjakan secara manual,sekarang dapat dimasukkan kedalam sistem sehingga data tersimpan dengan rapi dan selalu update.

\section{REFERENSI}

[1] Al-Fatta, Hanif(2011).Analisis dan Perancangan Sistem Informasi untuk Keunggulan Bersaing Perusahaan dan Organisasi Modern. Yogyakarta: Andi Offset.

[2] Al-Jufri, Hamid.(2011).Pengertian Sistem. Jakarta: Mitra Wacana Media.

[3] Al-Jufri, Hamid.(2011).Sistem Informasi Manajemen Pendidikan. Jakarta: Smart Grafika.

[4] As, Rosa dan shalahudin, M.(2011).Rekayasa Perangkat Lunak. Bandung: Modula Bandung.

[5] L.Gaol, Chr.Jimmy(2012).Sistem Informasi Manajemen Pemahaman dan Aplikasi. Jakarta: Grasindo.

[6] Laudon, Kenneth C.and Laudon, Jane P.(2011). Sistem Informasi Manajemen Mengelola Perusahaan Digital. Jakarta: Salemba Empat.

[7] Rochaety, E.(2011).Sistem Informasi Manajemen. Jakarta: Mitra Wacana Media.

[8] Sucipto(2011).Konsep dan Teknik Pengembangan Sistem Berbasis Teknologi Informasi. Banten: Dinas Pendidikan Propinsi Banten.

[9] Talib. Haer.(2011).Panduan Praktis Menguasai Komputer Jakarta: Elex Media Komputindo.

[10] Tantra, Rudy(2012).Manajemen Proyek Sistem Informasi. Yogyakarta: Andi Offset

[11] Widodo, Pudjo, Prabowo.dan Herlawati.(2011).Menggunakan UML. Bandung: Informatika. 